\title{
Posttraumatic stress response symptoms and quality of life in breast cancer patients after mastectomy and stress reduction program
} Vyacheslav Sushko1,2

\author{
Address: ${ }^{1}$ Department of Psychiatry, Odessa State Medical University, Odessa, Ukraine and ${ }^{2}$ Odessa Regional Cancer Hospital, Odessa, Ukraine \\ from International Society on Brain and Behaviour: 3rd International Congress on Brain and Behaviour \\ Thessaloniki, Greece. 28 November - 2 December 2007 \\ Published: 17 April 2008 \\ Annals of General Psychiatry 2008, 7(Suppl I):S230 doi:I0.I 186/I744-859X-7-SI-S230
}

This abstract is available from: http://www.annals-general-psychiatry.com/content/7/SI/S230

(c) 2008 Sushko; licensee BioMed Central Ltd.

\section{Background}

Posttraumatic stress is one of many psychological effects in breast cancer patients after mastectomy. Women fear mastectomy more than any surgery as believe, that after mastectomy they are expected with social problems (infringement of relations with the husband, loss of female appeal). Emotional problems are common after mastectomy, but patients differ in their vulnerability. Breast cancer patients experience enormous psychological stress after mastectomy, however, it is often unrecognized and untreated.

\section{Materials and methods}

The purpose of this study was to examine posttraumatic stress response symptoms and quality of life in breast cancer patients after mastectomy and stress reduction program. Women with recently diagnosed breast cancer $(\mathrm{n}=180)$ three days after surgery (mastectomy) completed the hospital anxiety and depression scale (HADS), quality of life scale and questionnaires that measured posttraumatic stress. The patients' of the clinical group participated in a 4-week stress reduction program that combines supportive psychotherapy, patient and family education and alfa-massage.

\section{Results}

The results of this study indicated that high posttraumatic stress index was significantly associated with the caregiver's burden, the patient's young age, the patient's symptoms and poor perception of her health. This study has demonstrated that 4-week stress reduction program was effective in decreasing symptoms of stress and improving overall quality of life in breast cancer patients after mastectomy.

\section{Conclusions}

Stress reduction program is a clinically useful adjunct to offer in breast cancer patients after mastectomy. 